\title{
Ongoing factors for consideration in the implementation of population-wide colorectal cancer screening
}

Hong Kong Med J 2016;22:295

DOI: 10.12809/hkmj164913

To the Editor-It is with great interest that I read the article "Alternatives to colonoscopy for population-wide colorectal cancer screening" by Leung et $\mathrm{al}^{1}$ in the February issue of the Hong Kong Medical Journal. Implementing a population-wide screening programme is complex, and should be based on evidence and cost-effectiveness. Australia's experience may be seen as a model for the multitude of factors to consider when establishing a programme in Hong Kong. The National Bowel Cancer Screening Program utilises an immunochemical faecal occult blood test kit mailed to all Australians aged 50, 55, 60 , and 65 years. Participants are able to collect the sample themselves at home. From 2015 to 2020, Australia is moving towards biennial screening for everyone between the ages of 50 and 74 years. $^{2}$

Participation in the programme is slowly increasing, with overall participation at about $36 \%{ }^{3}$ Nevertheless, a preliminary cost-effectiveness analysis in 2012 based on Australian data continued to demonstrate cost-effectiveness of this programme. ${ }^{4}$ Strategies to increase participation would further benefit population outcomes and cost-effectiveness. One of the strategies recently considered is endorsement of screening by the patient's general practitioner. Studies have shown that associating a patient's general practitioner or his/her clinic with an invitation letter enhances participation in screening programmes. ${ }^{5}$

Furthermore, all screening programmes must be coupled with political willpower and an understanding of screening issues by those who commit funding to the programme. Staged rollouts or limiting screening to certain age-groups may possibly be considered, but should always be based on evidence.

Samuel Hui *, MB, BS

Monash Health, Melbourne, Victoria, Australia

*Corresponding author: samhui59@gmail.com

\section{References}

1. Leung WC, Foo DC, Chan TT, et al. Alternatives to colonoscopy for population-wide colorectal cancer screening. Hong Kong Med J 2016;22:70-7.

2. Program overview, National Bowel Cancer Screening Program. Canberra: Australian Government; 2015 March 20. Available from: http://www.cancerscreening.gov.au/ internet/screening/publishing.nsf/Content/programoverview. Accessed Apr 2016.

3. Australian Institute of Health and Welfare 2015. National Bowel Cancer Screening Program: monitoring report 2013-14. Cancer series no. 94. Cat. no. CAN 92. Canberra: Australian Institute of Health and Welfare.

4. Tran B, Keating CL, Ananda SS, et al. Preliminary analysis of the cost-effectiveness of the National Bowel Cancer Screening Program: demonstrating the potential value of comprehensive real world data. Intern Med J 2012;42:794800.

5. Zajac IT, Whibley AH, Cole SR, et al. Endorsement by the primary care practitioner consistently improves participation in screening for colorectal cancer: a longitudinal analysis. J Med Screen 2010;17:19-24. 